\title{
Effects of infection time and moisture on development of ear blight and deoxynivalenol production by Fusarium spp. in wheat
}

\author{
By J LACEY ${ }^{1 \dagger}$, G L BATEMAN ${ }^{1 *}$ and C J MIROCHA ${ }^{2}$ \\ 'IACR-Rothamsted, Harpenden, Hertfordshire AL5 2JQ, UK \\ ${ }^{2}$ Department of Plant Pathology, University of Minnesota, St Paul, MN 55108-6030, USA
}

(Accepted 12 May 1999)

\begin{abstract}
Summary
Wheat ears were inoculated with conidia of Fusarium spp. at different growth stages between ear emergence and harvest and moist conditions were maintained for up to 7 days subsequently by mist irrigation. Of the fungi tested (Fusarium culmorum, F. avenaceum, F. tricinctum, F. sporotrichioides and Microdochium nivale), only $F$. culmorum produced ear blight symptoms and grain samples were found subsequently to contain deoxynivalenol. Most ear infection and deoxynivalenol formation occurred following inoculation at about mid-anthesis. Small amounts of deoxynivalenol were formed and some $F$. culmorum was isolated even in the absence of ear blight symptoms. An overnight wet period was sufficient to initiate infection and deoxynivalenol formation but both were increased by extending the wet period up to at least 3 days. Recovery of Fusarium spp. from harvested grain was usually possible whether or not symptoms developed. $F$. culmorum usually persisted and often increased to moderately high levels after storage for $7 \mathrm{wk}$ in a range of moisture conditions.
\end{abstract}

Key words: Wheat, ear blight, Fusarium spp., Fusarium culmorum, mycotoxins, deoxynivalenol

\section{Introduction}

Fungi are important causes of deterioration of growing and stored grains. Fusarium spp. are of particular importance in the growing crop. Ear infection of cereals can occur from anthesis to harvest and can result in contamination by a range of mycotoxins, including zearalenone and trichothecenes. The quantity and type of mycotoxin produced appear to be influenced by the weather before and after harvest and by the fungal species present. In surveys of UK wheat, mycotoxin levels have usually been found to be low but variable (Polley et al., 1991). This is not always the case elsewhere in Europe: in a survey of cereals in Bavaria from the 1987 harvest, some samples showed very high levels of contamination, including $44 \mathrm{mg}$ deoxynivalenol kg-1 in one wheat sample (Lepschy-von Gleissenthal et al., 1989). Data from other European studies also suggest that incidence and amounts in wheat might sometimes be high (e.g. Perkowski, Chełkowski \& Wakuliński, 1990; Perkowski, Wakuliński \& Chełkowski, 1990).

Conditions that influence the production of mycotoxins are little known although zearalenone production is initiated at relatively low temperatures (Sutton, 1982). Unusually, some growth of Fusarium can occur in stored grain (Lacey, 1990), but this requires moisture conditions (water activity) above about $0.87 \mathrm{a}_{\mathrm{w}}$ at temperatures between about 0 and $35^{\circ} \mathrm{C}$, with the optimum about $25^{\circ} \mathrm{C}$ (Magan \& Lacey, 1984). Critical studies on environmental conditions and infection have concerned particularly $F$. graminearum Schwabe on maize and wheat in
Canada, where it is associated with wet weather at anthesis (Sutton, 1982) and where most of the inoculum is wind-dispersed ascospores. This was confirmed in European conditions (Suty \& MaulerMachnik, 1996). F. culmorum (W. G. Sm.) Sacc., the predominant species in Britain, is splash-dispersed as asexual conidia. Ear infection by F. culmorum and other species is also greatest in Britain in wet conditions in summer (Jones et al., 1997).

This paper reports a series of field experiments designed to investigate critical infection times and wet periods during infection on the development of ear blight and mycotoxins in wheat by Fusarium spp.

\section{Materials and Methods}

Fungal inoculum

Fusarium species isolated from crops at Rothamsted were used in all experiments. Isolates represented $F$. avenaceum (Fr.) Sacc., $F$. culmorum, $F$. sporotrichioides Sherb. (originally identified as F. poae (Peck) Wollenw. (Bateman, Kwaśna \& Ward, 1996; Ramakrishna, Lacey \& Smith, 1996)), F. tricinctum (Corda) Sacc. and Microdochium (Fusarium) nivale (Fr.) Samuels \& Hallett. Cultures were lyophilised for storage and during the period of inoculum preparation were maintained on $2 \%$ malt extract agar with subculturing as necessary. Three different isolates of each species were generally mixed for use as inoculum in each experiment. In the first year's experiment, inoculum was prepared on $2 \%$ 
Table 1. Inoculation and irrigation treatments

\begin{tabular}{|c|c|c|}
\hline Treatment date & Growth stage & Irrigation \\
\hline \multicolumn{3}{|l|}{1994} \\
\hline 23 June & 63 & none \\
\hline 24 June & 63 & Intermittent (non-inoculated) \\
\hline 29 June & $67-69$ & Intermittent \\
\hline 2 July & $69-71$ & $\begin{array}{l}\text { Intermittent to } 4 \text { July, then } \\
\text { continuous }\end{array}$ \\
\hline 6 July & $71-75$ & Continuous but off $24-h, 8-9$ \\
\hline \multicolumn{3}{|r|}{ - } \\
\hline 14 July & $77-81$ & Continuous \\
\hline 21 July & $85-89$ & Continuous \\
\hline 27 July & $89-91$ & Continuous \\
\hline \multicolumn{3}{|l|}{1995} \\
\hline 1 June & $51-57$ & Continuous \\
\hline 9 June & $59-63$ & Continuous \\
\hline 15 June & $61-69$ & Continuous \\
\hline 21 June & $69-71$ & Continuous \\
\hline 21 June & $69-71$ & None following inoculation, then \\
\hline 3 & & days on, 3 days off for \\
\hline 12 days, to & & flattened crop \\
\hline 27 June & $71-75$ & Continuous \\
\hline 3 July & $75-81$ & Continuous \\
\hline 10 July & 85 & Continuous \\
\hline 10 July & 85 & None following inoculation, then \\
\hline 3 & & days on, 3 days off for \\
\hline 12 days, to & & flattened crop \\
\hline \multicolumn{3}{|l|}{1996} \\
\hline 10 June & 53 & None, half, 1 or 3 days (to all \\
\hline 16 June & 65 & plots, subdivided) \\
\hline 19 June & 69 & \\
\hline 23 June & 71 & \\
\hline 27 June & 71 & \\
\hline 30 June & 73 & \\
\hline 5 July & 75 & \\
\hline 10 July & 77 & \\
\hline
\end{tabular}

malt extract agar in Petri dishes and incubated at $25^{\circ} \mathrm{C}$ for 7-10 days. When required, conidia were suspended in sterile distilled water by washing the agar surface with gentle teasing using a disposable plastic spreader. Conidial suspensions were filtered through muslin before use. In the two subsequent years, cultures were grown in Bilai's liquid medium (Joffe, 1963). Spore concentrations were standardised at approximately $10^{6} \mathrm{ml}^{-1}$.

\section{Field experiments}

There were three experiments in successive years on two adjacent sites in the same field at Rothamsted farm. Each was in a first winter wheat crop, cv. Hussar sown at 380 seeds $\mathrm{m}^{-2}$, following winter oilseed rape (1994 experiment) or winter oats (1995 and 1996 experiments). The 1996 experiment was on the same site as the 1994 experiment. Each experiment had a randomised block design with two complete blocks of nine main plots. Plots were 14-17 $\mathrm{m} \times 4 \mathrm{~m}$ with $2-\mathrm{m}$ sown guard areas between plots and a $1-\mathrm{m}$ path between blocks to accommodate irrigation lines. Randomised subplots for inoculation treatments were marked out within each plot. In 1994, each of six subplots $(1 \mathrm{~m} \times 1 \mathrm{~m})$, in two rows of three, was inoculated with a $100-\mathrm{ml}$ spore suspension of one of the five Fusarium spp. (a mixture of isolates) or used as the uninoculated control. In 1995, each of four subplots $(1 \mathrm{~m} \times 4 \mathrm{~m})$ was inoculated with a $200-\mathrm{ml}$ spore suspension of one of three Fusarium spp., or left uninoculated. In 1996, each of four subplots $(1 \mathrm{~m} \times 4 \mathrm{~m})$ was inoculated with a $200-\mathrm{ml}$ spore suspension of $F$. culmorum, a fifth with $F$. sporotrichioides and a sixth was left uninoculated. Spore suspensions were applied using a hand-held pressure sprayer. Mist irrigation (Access Irrigation Ltd, Northampton) was provided after inoculation by three rows of misting nozzles on $1-\mathrm{m}$ poles at $2-\mathrm{m}$ intervals along the length of the plot, one row along each side of the plot and one along its centre. Mist application was controlled by a wet-leaf sensor placed in the crop to maintain moist conditions after inoculation to enhance infection. The misting lines were moved from plot to plot as required, with two replicate plots (the most that could be accommodated by the apparatus) misted in immediate succession at intervals determined by the wet leaf sensor in one of the plots. During 1994 and 1995, ears were inoculated at different growth stages from ear emergence to harvest and were irrigated for 6 days after inoculation (Table 1). In 1996, plots were inoculated from just before anthesis and each was divided into four parts receiving, respectively, no irrigation, overnight irrigation only (half day), 1 day of irrigation or 3 days of irrigation (Table 1). Plots inoculated with $F$. sporotrichioides were situated in the 3-day irrigation section.

Ear blight was assessed by counting diseased (with necrotic lesions visible on one or more spikelets) and healthy ears along four randomly chosen rows across the plot at the time that it was most evident and before all the ears markedly changed colour.

All the ears from each subplot were harvested by hand when the grain was ripe (growth stage, GS, 92; Zadoks, Chang \& Konzak, 1974) and subsamples of the harvested grain were used for fungal isolations (1995) and mycotoxin analyses.

\section{Fungal isolations}

The percentage of grains contaminated by Fusarium spp. was determined in at least 50 grains taken from 10 ears from each subplot 1 wk after inoculation in 1994 and 1995. This was done usually by placing 25 grains that were surface-sterilised in $10 \%$ Chloros (sodium hypochlorite) for $5 \mathrm{~min}$ and 25 unsterilised grains from each plot on to $2 \%$ malt extract agar. Potato dextrose agar containing the fungicide dichloran ( $2 \mathrm{mg}$ litre $^{-1}$ ) was used additionally on most occasions and gave similar results. Colonies were identified and counted after incubating for 7 days at $25^{\circ} \mathrm{C}$.

In 1995 , the survival of $F$. culmorum, the most effective inoculant fungus, on grain harvested from selected plots was tested at $15^{\circ} \mathrm{C}$ and $25^{\circ} \mathrm{C}$ at a range of water activities (cf. Magan \& Lacey, 1984). Petri dish 
Table 2. Fusarium on grain 1 wk after inoculation and concentration of deoxynivalenol (DON) in ripe grian after inoculation with $\mathrm{F}$. culmorum, 1994

\begin{tabular}{lccccc}
\hline & \multicolumn{4}{c}{ Logit \% grains with fungus (back transformation) } & \\
\cline { 2 - 6 } Growth stage at inoculation & F. avenaceum & F.culmorum & F. sporotrichioides & F. tricinctum & DON $\left(\mu \mathrm{g} \mathrm{g}^{\prime}\right.$ ) \\
\hline 63 & $-1.62(3.3)$ & $-1.68(2.8)$ & $-2.03(1.2)$ & $-2.31(0.5)$ & 2.45 \\
$67-69$ & $-0.60(22.6)$ & $-0.06(46.5)$ & $-1.27(6.8)$ & $-0.88(14.1)$ & 1.16 \\
$69-71$ & $-0.35(32.7)$ & $0.42(69.2)$ & $-1.40(5.2)$ & $-0.70(19.4)$ & 0.97 \\
$71-75$ & $-0.38(31.6)$ & $-0.04(47.5)$ & $-0.62(21.8)$ & $-0.68(20.0)$ & 1.07 \\
$77-81$ & $-0.42(29.9)$ & $0.50(72.6)$ & $-1.31(6.2)$ & $-1.22(7.5)$ & 0.35 \\
$85-89$ & $-0.55(24.4)$ & $-0.16(41.5)$ & $-1.75(2.4)$ & $-1.39(5.3)$ & - \\
$89-91$ & $-0.12(43.4)$ & $1.01(87.8)$ & $-1.13(8.9)$ & $-0.79(16.5)$ & - \\
SED (6 df) & 0.243 & 0.432 & 0.333 & 0.296 & $0.157(4 \mathrm{df})$ \\
\hline
\end{tabular}

"The data in each column show frequencies only of the species inoculated (shown in column heading): a separate analysis of variance was done for each inoculated species and excluded subplots that were inoculated with other species or were uninoculated.

- zero values. excluded from the analysis of variance.

lids, each containing a layer of grain, were placed over seed trays containing saturated salt solutions to maintain the required water activities. A solution of $\mathrm{K}_{2} \mathrm{SO}_{4}$ was used for $0.98 \mathrm{a}_{w}$ at both temperatures, $\mathrm{KNO}_{3}\left(15^{\circ} \mathrm{C}\right)$ or $\mathrm{Pb}\left(\mathrm{NO}_{3}\right)_{2}\left(25^{\circ} \mathrm{C}\right)$ for $0.95 \mathrm{a}_{\mathrm{w}}$ and $\mathrm{MgSO}_{4} .7 \mathrm{H}_{2} 0\left(15^{\circ} \mathrm{C}\right)$ or $\mathrm{BaCl}_{2}\left(25^{\circ} \mathrm{C}\right)$ for $0.90 \mathrm{a}_{\mathrm{w}}$. Ten grains from each treatment were removed after 1, 2, 3 and 7 wk and incubated on malt extract agar.

\section{Mycotoxin analysis}

Mycotoxins were analysed in grain subsamples, harvested from subplots inoculated with $F$. culmorum and from non-inoculated control subplots, using gas chromatography linked to mass spectrometry with selected ion monitoring (Mirocha et al., 1998). Samples were analysed as trimethylsilyl ether derivatives on a Shimadzu QP-5000 GC/MS using a $30 \mathrm{~m}$ fused silica gas chromatography column. Injector and detector inlet temperatures were, respectively, 300 and $280^{\circ} \mathrm{C}$. The oven temperature was programmed to increase from $80^{\circ} \mathrm{C}$ to $280^{\circ} \mathrm{C}$ at $25^{\circ} \mathrm{C} \mathrm{min}$ min $^{-1}$ and then held at $280^{\circ} \mathrm{C}$ for $5 \mathrm{~min}$ with a constant flow of

Table 3. Incidence of ear blight and concentration of deoxynivalenol (DON) in harvested grain after inoculation with Fusarium culmorum, 1995

\begin{tabular}{lcc}
\hline $\begin{array}{l}\text { Growth stage } \\
\text { at inoculation }\end{array}$ & $\begin{array}{c}\text { Logit \% ear blight } \\
\text { (back-transformation) }\end{array}$ & DON $\mu \mathrm{g} \mathrm{g}^{\prime \prime}$ \\
\hline Not inoculated & - & 0.04 \\
$51-57$ & $-1.27(6.8)$ & 0.16 \\
$59-63$ & $-1.37(5.6)$ & 0.81 \\
$61-69$ & $-0.15(42.1)$ & 12.12 \\
$69-71$ & $-1.76(2.4)$ & 0.40 \\
$71-75$ & - & 1.69 \\
$75-81$ & - & 0.55 \\
85 & - & 0.10 \\
SED & $0.088(3 \mathrm{df})$ & $0.848(7 \mathrm{df})$ \\
\hline
\end{tabular}

- zero values. excluded from the analysis of variance.

"Data are from those plots in which the crop was not flattened artificially (see text and Table 2). helium at $1 \mathrm{ml} \mathrm{min} \mathrm{m}^{-1}$. A standard curve was run with each batch of grain samples, with the standards interspersed among the samples being analysed. Selected ion monitoring utilised fragment ions $(\mathrm{m} / \mathrm{z}$ values) of $235.15,422.25,392.20,482.30,377.20,480.30$, $570.30,585.30,333.10,289.15$ and 151.15 as determinants. The $\mathrm{m} / \mathrm{z}$ value 235 was used as the general quantitative fragment for most of the deoxynivalenol derivatives, 235, 422 and 392 for deoxynivalenol, 392 and 482 for 3-acetyldeoxynivalenol and 15acetyldeoxynivalenol, 289 and 482 for nivalenol, 480 and 570 for fusarenon- $X$ and 333 and 151 for zearalenone.

\section{Results}

\section{4}

Ear emergence was between 10 and 16 June but, because of problems with the irrigation equipment, inoculation was delayed until 23 June (GS 63) when the first subplots to be inoculated (with $F$. avenaceum, $F$. culmorum, F. sporotrichioides, F. tricinctum or $M$. nivale) were those in the two non-irrigated control plots. Initially, only intermittent irrigation was possible because of equipment faults. On most days irrigation was applied four to six times for 3-5 min. The first plots to be both inoculated and irrigated were inoculated on 29 June. Continuous misting was possible after 4 July, but harvest prevented inoculation of the final two plots in the experiment. Table 1 shows a full list of treatments.

No disease identifiable as ear blight caused by Fusarium was seen in any plot. However, some ears had a bleached appearance at about GS 81-85. This was most frequent in plots inoculated with $F$. culmorum at GS 63 but not irrigated, and affected half the plants. The effectiveness of inoculation was assessed by isolating Fusarium spp. from grain 1 wk after treatment; inoculation at GS 67-69 or later resulted in greatest frequency of isolations of 
F. culmorum (Table 2). Seed from inoculated subplots also carried a range of Fusarium spp. other than the inoculant, mainly $F$. culmorum. Such contaminants were isolated from up to $50 \%$ of seeds but were fewest after inoculation with $F$. culmorum. The frequencies of isolation, over all inoculation times, also differed among the inoculated species after harvest. These frequencies were: $F$. avenaceum, $47.3 \% ; F$. culmorum, $79.0 \% ; F$. sporotrichioides, $7.4 \% ; F$. tricinctum, 29.7\%; $M$. nivale, $0.3 \%$ (a single isolation). Considering all isolation methods, approximately $20-25 \%$ of harvested seeds carried Fusarium spp. F. culmorum was also isolated from almost $25 \%$ of surface-sterilised seeds, suggesting seed infection, but less than $8 \%$ of surface-sterilised seeds inoculated with other species yielded the inoculant species.

Samples taken from each plot inoculated with $F$. culmorum were analysed to determine their deoxynivalenol content. Most deoxynivalenol (2.45 $\mu \mathrm{g} \mathrm{g}^{-1}$ ) was found in grain inoculated at GS 63, despite lack of irrigation (Table 2). From GS 67-91 to GS 71-75, deoxynivalenol contamination remained close to $1 \mu \mathrm{g} \mathrm{g}^{-1}$ and none was recovered after GS
$85-89$. None was found in uninoculated wheat with irrigation.

1995

Ear emergence occurred at the beginning of June and the first inoculation treatment was on 1 June (GS 51-57). Thereafter, two plots were inoculated each week until GS 85 was reached, with a further two plots inoculated at GS 69-71 and 85 (Table 1). Because of their poor recovery after inoculation in 1994, $F$. sporotrichioides and $M$. nivale were not used in 1995. Ear blight was assessed on 7 July at about GS 83. At this stage, there was considerable disease $(42 \%$ of ears affected) in plots inoculated at GS 61-69 with F. culmorum and much less in plots inoculated earlier or later, with none seen for inoculations after GS 69-71 (Table 3) or in plots inoculated at any growth stage with $F$. avenaceum or $F$. tricinctum. Despite the amount of ear disease from the GS 61-69 inoculation, recovery of Fusarium spp. from inoculated ears was low. However, recovery for inoculations at GS 69-71, except for $F$. tricinctum, was greater than for earlier inoculations (Table 4). Fusarium spp. were recovered at trace levels where no inoculum was applied and was absent from most such plots.

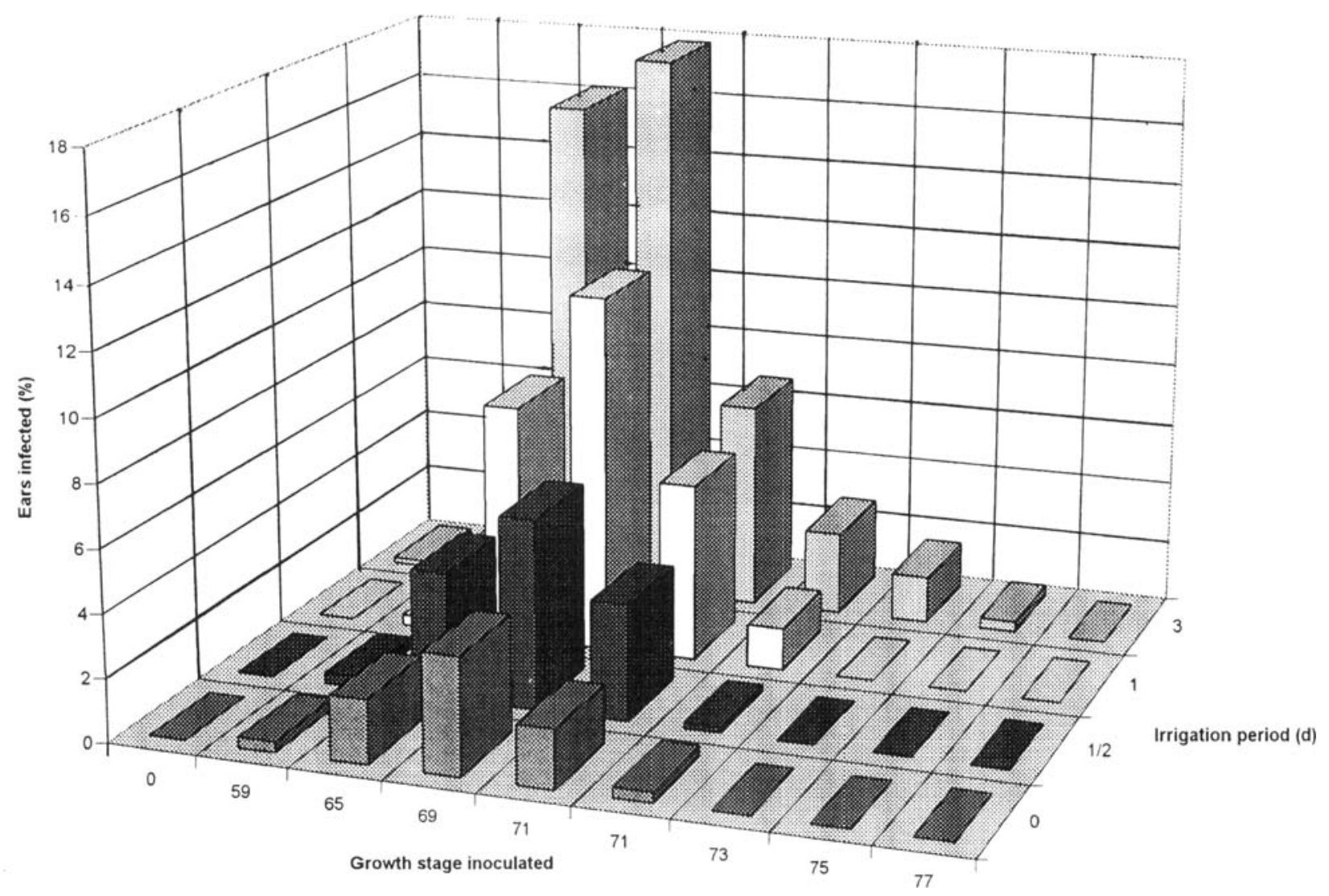

Fig. 1. Ear blight in wheat after different periods of irrigation following inoculation at different times with Fusarium culmorum, 1996 . SEDs: 1.06 (15 df) for comparisons between different periods of irrigation; $1.44(9 \mathrm{df})$ for comparisons between different inoculation times. 
Most deoxynivalenol contamination of grain $\left(12 \mu \mathrm{g} \mathrm{g}^{-1}\right)$ occurred after inoculation with F. culmorum at GS 61-69; about $1 \mu \mathrm{g} \mathrm{g} \mathrm{g}^{-1}$ occurred for earlier and later dates (Table 3). It was evident that low levels of deoxynivalenol were present in the absence of visible ear blight. No deoxynivalenol was found in grain inoculated at GS 69-71 or GS 85 without irrigation immediately afterwards and then flattened to simulate lodging before receiving alternating 3-day wet and dry periods over the 12 days immediately before harvest.

The behaviour of $F$. culmorum in stored grain was tested by incubating samples of infected grain from irrigated plots, inoculated at GS 61-69, at different water activities and temperatures. F. culmorum was recovered from $41-45 \%$ of grains from inoculated plots after incubation for 1 wk at $15^{\circ} \mathrm{C}$ with further increase up to $7 \mathrm{wk}$ at $0.98 \mathrm{a}_{\mathrm{w}}$ (Table 5). F. culmorum behaved similarly on grain from plots inoculated with $F$. avenaceum, although its recovery was more variable on grain from plots inoculated with $F$. tricinctum (results not shown). The results at the two temperatures showed small differences; in particular, infection in treatments other than $F$. culmorum inoculation was usually less at the higher temperature. Greatest frequency occurred in grain from plots inoculated at GS 61-69, except after incubation for $7 \mathrm{wk}$ at $15^{\circ} \mathrm{C}$ and $0.98 \mathrm{a}_{w}$ when most grains from plots inoculated at any growth stage were heavily colonised (results not shown).

\section{6}

The experimental procedure was changed to allow assessment of the effects of different wet periods up to 3 days on infection by $F$. culmorum and deoxynivalenol production. Inoculations were also concentrated over a shorter period by inoculating at 3-6-day intervals instead of weekly (Table 1). A fur-

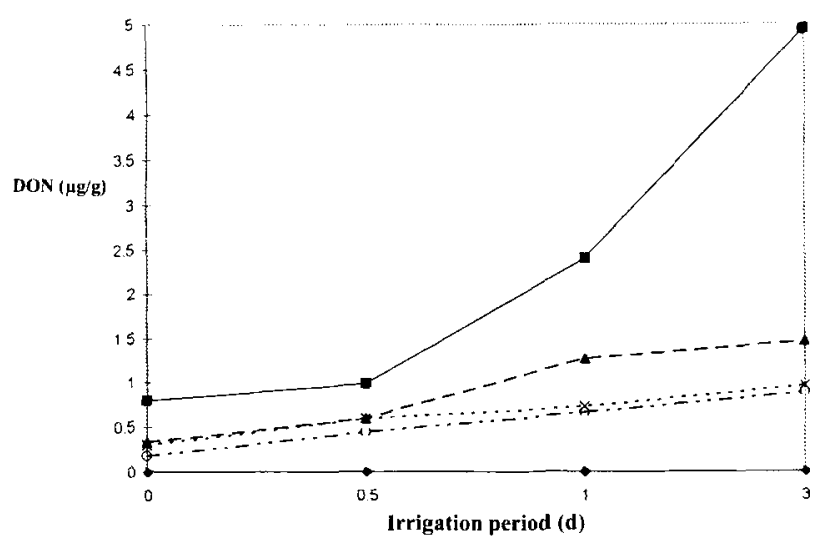

Fig. 2. Deoxynivalenol (DON) concentrations in wheat grain after different periods of irrigation following inoculation at differen times with Fusarium culmorum, 1996. SEDS: 0.123 (12 df) for comparisons between different periods of irrigation; 0.129 (12 df) for comparisons between inoculation times. Inoculations were at GS $53(\diamond), 65(\square), 69(\Delta), 71,23$ June $(X), 71,29$ June $(O)$
Table 4. Fusarium spp. "on grain 1 wk after inoculation, 1995

\begin{tabular}{|c|c|c|c|}
\hline \multirow{2}{*}{$\begin{array}{l}\text { transformation) } \\
\text { Growth stage }\end{array}$} & \multicolumn{3}{|c|}{ Logit \% grains with fungus (back- } \\
\hline & $F$. avenaceum & F. culmorum & F. tricinctum \\
\hline $69-71^{b}$ & $-2.03 \quad(1.2)$ & $-1.33 \quad(6.1)$ & $-2.03 \quad(1.2)$ \\
\hline $51-57$ & $-1.62 \quad(3.3)$ & $-1.62 \quad(3.3)$ & $-1.30(6.4)$ \\
\hline $59-63$ & $-0.74(18.1)$ & $-0.68(20.0)$ & $-1.30 \quad(6.4)$ \\
\hline $61-69$ & $-1.22 \quad(7.5)$ & $-1.18 \quad(8.1)$ & $-1.62(3.3)$ \\
\hline $69-71$ & $-0.65(20.9)$ & $-0.26(36.8)$ & -1.81 \\
\hline $71-75$ & $-0.44(28.9)$ & $-0.44(28.8)$ & $-0.44(28.8)$ \\
\hline $75-81$ & $-0.65(21.1)$ & $-0.24(37.9)$ & $-0.82(15.8)$ \\
\hline 85 & $-1.81 \quad(2.1)$ & $-0.33(33.4)$ & $-1.81 \quad(2.1)$ \\
\hline $\operatorname{SED}(7 \mathrm{df})$ & 0.245 & 0.217 & 0.338 \\
\hline
\end{tabular}

The data in each column show frequencies only of the species inoculated (shown in column heading); a separate analysis of variance was done for each inoculated species and excluded subplots that were inoculated with other species or were inoculated.

"no irrigation

ther plot receiving irrigation for 3 days was inoculated with $F$. sporotrichioides. Ear emergence started at the beginning of June and was complete by 10 June when the first inoculation treatment was applied. Anthesis progressed much more quickly than in 1995 and the next inoculation was on 16 June.

Ear blight was assessed after GS 77 from 12-20 July. Plots inoculated with $F$. culmorum at GS 65 and 69 and irrigated for 3 days were the most heavily affected ( 16.2 and $17.8 \%$ of ears, respectively) (Fig. 1). The amount of ear blight fell sharply on either side of these inoculation dates. It also decreased with decreasing wet period although $3.7 \%$ of ears were affected after inoculation at GS 69 , even without irrigation.

Deoxynivalenol also decreased with decreasing wet period although $0.8 \mu \mathrm{g} \mathrm{g} \mathrm{g}^{-1}$ was produced without any irrigation (Fig. 2). Deoxynivalenol was measured only for 3-day irrigation treatments for inoculations made after GS 71. After irrigation for 3 days, most deoxynivalenol was produced by inoculation at GS 65 , the concentrations decreasing sharply for later inoculations. Concentrations $\left(\mu \mathrm{g} \mathrm{g}^{-1}\right)$ for inoculations at GS 65, 69, 71 (23 June), 71 ( 27 June), 73, 75 and 77 with 3 days' irrigation were, respectively, 4.95 , $1.47,0.96,0.88,0.71,0.11$ and 0.33 (SED $=0.414,6$ df).

\section{Discussion}

These experiments have shown that the time of infection by $F$. culmorum that produces the greatest amount of ear infection and of deoxynivalenol contamination is restricted to a short period during anthesis. Little or no disease resulted from inoculation between ear emergence and the start of anthesis and amounts decreased steeply for inoculations after about mid-anthesis (GS 65). Contamination with deoxynivalenol was greatest after inoculation at about 
Table 5. Fusarium culmorum on grain stored for 1, 2 or $3 w k$ in different conditions

\begin{tabular}{|c|c|c|c|c|c|}
\hline \multirow[b]{2}{*}{ Temperature $\left({ }^{\circ} \mathrm{C}\right)$} & \multirow[b]{2}{*}{ Water activity $\left(a_{w}\right)$} & \multicolumn{4}{|c|}{ Logit $\%$ grains with $F$. culmorum (back-transformation) } \\
\hline & & $1 \mathrm{wk}$ & $2 \mathrm{wk}$ & $3 w k$ & $7 \mathrm{wk}$ \\
\hline 15 & 0.98 & $-0.09(45)$ & $0.30(64)$ & $0.24(61)$ & $0.64(78)$ \\
\hline 15 & 0.95 & $-0.08(45)$ & $-0.34(33)$ & $-0.41(30)$ & -0.30 \\
\hline 15 & 0.90 & $-0.17(41)$ & $-0.45(28)$ & -0.43 & $-0.60(23)$ \\
\hline 25 & 0.98 & $-0.06(46)$ & $-0.02(49)$ & $0.04(52)$ & $0.30(64)$ \\
\hline 25 & 0.95 & -0.29 & $-0.29(36)$ & -0.34 (33) & $-0.88(14)$ \\
\hline 25 & 0.90 & $-0.38(31)$ & $-0.16(42)$ & $-0.17(41)$ & $-0.31(34)$ \\
\hline $\operatorname{SED}(16 \mathrm{df})$ & & 0.205 & 0.154 & 0.188 & 0.212 \\
\hline
\end{tabular}

mid-anthesis, but small amounts (approximately $1 \mu \mathrm{g} \mathrm{g}^{-1}$ ) were produced following inoculation at other times, at least to the late milk-early dough stages (GS 77-83), without visible disease. Disease and deoxynivalenol contamination increased with increasing wet period from $1 / 2$ to at least 3 days and it is possible that the differences in the maximum deoxynivalenol contamination found each year might be explained by the amount of wetting that they received: intermittent in $1994\left(2.4 \mu \mathrm{g} \mathrm{g}^{-1}\right)$ and continuous for 6 days in $1995\left(12 \mu \mathrm{g} \mathrm{g}^{-1}\right)$ and for 3 days in $1996\left(4.9 \mu \mathrm{g} \mathrm{g}^{-1}\right)$. Inoculation without immediate misting followed by misting under simulated lodging conditions failed to produce any deoxynivalenol contamination. Nivalenol was never detected. $F$. avenaceum and $F$. culmorum persisted on stored grain after inoculation, even without visible disease, in a range of conditions, that might also influence mycotoxin content by the time the grain is used. Amounts of deoxynivalenol were found not to change after $6 \mathrm{wk}$ in storage in normal commercial conditions (Young et al., 1984). Moist grain, as tested here, also allows invasion by $F$. graminearum when stored in cool conditions (Sherwood \& Peberdy, 1974). Isolates previously thought to be $F$. poae have been found to be atypical isolates of $F$. sporotrichioides (Bateman, Kwaśna \& Ward, 1996; Ramakrishna, Lacey \& Smith, 1996) and appear to represent the first record of this species in Britain. This raises the possibility of contamination by T-2 toxin although this has, so far, not been demonstrated.

Deoxynivalenol is one of the less toxic trichothecenes produced by Fusarium spp. The isomers, 3-acetyldeoxynivalenol and 15acetyldeoxynivalenol are about twice as toxic to humans and animals and nivalenol is 10 times more toxic (Snijders, 1990). However, only $0.3 \mu \mathrm{g}$ deoxynivalenol $\mathrm{g}^{-1}$ of feed is sufficient to decrease consumption by pigs and cause poor weight gain and economic losses. Agriculture Canada advises that grain fed to animals should contain less than $1 \mu \mathrm{g} \mathrm{g}$ ${ }^{\prime}$ and grain fed to pregnant or lactating animals should be uncontaminated (Snijders, 1990). Contamination in the winter wheat experiments regularly exceeded these levels. Swedish regulations limit the contami- nation of swine feed to $0.5 \mu \mathrm{g} \mathrm{g}^{-1}$ and of cattle feed to $2 \mu \mathrm{g} \mathrm{g}{ }^{-1}$ (Snijders, 1990). A tolerable daily intake for humans is $3 \mu \mathrm{g} \mathrm{kg}^{-1}$ body weight for adults and 1.5 $\mu \mathrm{g} \mathrm{kg}^{-1}$ for children (Snijders, 1990). Deoxynivalenol, at $0.02-0.4 \mu \mathrm{g} \mathrm{g}^{-1}$, was found in 32 of 199 UK homegrown wheat samples taken in the three years, 1980 1982 (Osborne \& Willis, 1984).

Rainfall has been shown to be an important factor in determining the occurrence of ear infection by Fusarium although there were also correlations with relative humidity and prevalence of infection in the previous season (Snijders, 1990). There have been no previous detailed studies on the conditions necessary for $F$. culmorum to infect winter wheat and cause deoxynivalenol contamination. However, Sutton (1982) studied the epidemiology of $F$. graminearum ear blight in wheat and maize. Unlike $F$. culmorum, $F$. graminearum produces wind-dispersed ascospores as well as splash-dispersed conidia. Both have a role in the disease in Canada. Susceptibility of wheat to $F$. graminearum infection is well known and anthers have sometimes been associated with infection. Infection is considered to occur between anthesis and the soft dough stage (GS 85). However, our results suggest that the period of susceptibility to $F$. culmorum is much more limited. Such a restricted period of susceptibility presents difficulties for timing a chemical control. Infection by $F$. graminearum requires relatively high temperatures $\left(20-30^{\circ} \mathrm{C}\right)$ and 48-60 h surface wetness. Few infections occur with less than $24 \mathrm{~h}$ surface wetness. F. culmorum generally predominates in climates cooler than those most favourable for $F$. graminearum. A few infections of $F$. culmorum were able to occur without misting and the frequency increased with increasing wet period to at least $72 \mathrm{~h}$. However, toxin production also occurred without visible symptoms of infection.

\section{Acknowledgements}

The research at IACR-Rothamsted was funded by the Ministry of Agriculture, Fisheries and Food. We thank Mrs P Williamson for assistance with the experiments. 


\section{References}

Bateman G L, Kwaśna H, Ward E. 1996. Relationships among Fusarium spp. estimated by comparing restriction fragment length polymorphisms in polymerase chain reaction-amplified nuclear rDNA. Canadian Journal of Microbiology 42:1232-1240.

Joffe A Z. 1963. The mycoflora of a continuously cropped soil in Israel, with special reference to effects of manuring and fertilising. Mycologia 55:271-282.

Jones D R, Jenkinson P, Clement J A, Turner J A, Jennings P, Gladders P. 1997. Epidemiology and control of Fusarium ear blight. Project Report No. 143. London: Home-Grown Cereals Authority, pp. 1-66.

Lacey J. 1990. Mycotoxins in UK cereals and their control. As pects of Applied Biology 25, Cereal Quality II, pp. 395-405.

Lepschy-von Gleissenthal J, Deitrich R, Martlbauer E, Schuster M, Süss A, Terplan G. 1989. A survey on the occurrence of Fusarium mycotoxins in Bavarian cereals from the 1987 harvest. Zeitschrift für Lebensmittel-Untersuchung und -Forschung 188:521-526.

Magan N, Lacey J. 1984. Effect of temperature and pH on water relations of field and storage fungi. Transactions of the British Mycological Society 82:71-81.

Mirocha C J, Kolaczkowski E, Xie W, Yu H, Jelen H. 1998 Analysis of deoxynivalenol and its derivatives (batch and single kernel) using gas chromatography/mass spectrometry. Journal of Agricultural and Food Chemistry 46:1414-1418.

Osborne B G, Willis K H. 1984. Studies into the occurrence of some trichothecene mycotoxins in UK home-grown wheat and in imported wheat. Journal of the Science of Food and Agriculture 35:579-583.

Perkowski J, Chełkowski J, Wakuliński W. 1990. Mycotoxins in cereal grain. Part 13. Deoxynivalenol and 3-acetyldeoxynivalenol in wheat kernels and chaff with head fusariosis symptoms. Die Nahrung 34:325-328.
Perkowski J, Wakuliński W, Chełkowski J. 1990. Natural occurrence of deoxynivalenol 3-acetyldeoxynivalenol and zearalenone in wheat in 1988. Microbiologie-Aliments- $\mathrm{Nu}_{\mathrm{t}}$ trition 8:241-247.

Polley R W, Turner J A, Cockerell V, Robb J, Scudamore K A, Sanders, M F, Magan N. 1991. Survey of Fusarium species infecting winter wheat in England, Wales and Scotland, 1989 \& 1990. Project Report No. 39 London: Home-Grown Cereals Authority, pp. 1-100.

Ramakrishna N, Lacey J, Smith J E. 1996. Patterns of Fusarium sporotrichioides colonization and $\mathrm{T}-2$ toxin formation in barley grain. Food Additives and Contaminants 13:939-948.

Sherwood R F, Peberdy J F. 1974. Production of the mycotoxin. zearalenone, by Fusarium graminearum growing on stored grain. I. Grain storage at reduced temperatures. Journal of the Science of Food and Agriculture 25:1081-1087.

Snijders C H A. 1990. Fusarium head blight and mycotoxin contamination of wheat, a review. Netherlands Joumal of Plant Pathology 86: 187-198.

Sutton J C. 1982. Epidemiology of wheat head blight and maize ear rot caused by Fusarium graminearum. Canadian Journal of Plant Pathology 4: 195-209.

Suty A, Mauler-Machnik A. 1996. Fusarium head blight on wheat - new findings on the epidemiology and control of Gibberella zeae the telemorph of Fusarium graminaerum with Folicur ${ }^{\circledR}$. Pflanzenschutz-Nachricten Baver 49:55-70.

Young J C, Fulchner R G, Hayhoe J H, Scott P M, Dexter J E. 1984. Effect of milling and baking on deoxynivalenol (vomitoxin) content on eastern Canadian wheats. Journal of Agricultural and Food Chemistry 32:659-664.

Zadoks J C, Chang T T, Konzak C F. 1974. A decimal code for the growth stages of cereals. Weed Research 14:415-421.

(Received 22 April 1999) 